\title{
Growth and reproduction patterns of the winged pearl oyster, Pteria sterna, cultivated in tropical environments of Mexico: Implications for pearl farming
}

\section{Patrones de crecimiento y reproducción de la concha nácar, Pteria sterna, cultivada en un ambiente tropical de México: Implicaciones para el cultivo de perlas}

\author{
Irene Serna-Gallo ${ }^{1}$, Javier MJ Ruíz-Velazco ${ }^{1,2}$, Héctor Acosta-Salmón ${ }^{3}$, Emilio Peña-Messina ${ }^{1,2}$, \\ Guadalupe Torres-Zepeda ${ }^{4}$, Pedro E Saucedo ${ }^{3 *}$ \\ ${ }^{1}$ Posgrado en Ciencias Biológico Agropecuarias, Universidad Autónoma de Nayarit (UAN), Ciudad de la \\ Cultura Amado Nervo, CP 63190 Tepic, Nayarit, México. \\ 2 Escuela Nacional de Ingeniería Pesquera, Universidad Autónoma de Nayarit (UAN), San Blas, Nayarit, \\ México. \\ ${ }^{3}$ Centro de Investigaciones Biológicas del Noroeste (CIBNOR), Av. Instituto Politécnico Nacional 195, Col. \\ Playa de Santa Rita Sur, CP 23090 La Paz, Baja California Sur, México. \\ ${ }^{4}$ Unidad Académica de Ecología Marina, Universidad Autónoma de Guerrero (UAG), Av. Gran Vía Tropical, \\ Acapulco, Guerrero, México.
}

*Corresponding author. E-mail: psaucedo04@cibnor.mx

\begin{abstract}
The winged pearl oyster, Pteria sterna, sustains a growing pearl industry in northwestern Mexico, where a subtropical climate prevails. In tropical areas of Mexico, pearl cultivation may be profitable, but insufficient information on the biology and ecology of the species limits the definition of protocols for creating pearl farms. We measured absolute growth, growth rate, reproductive stages, changes in oocyte size, and size at first maturity of juvenile P. sterna cultivated in Bahía de Acapulco over one annual cycle (2009-2010), and compared their response in this tropical area with reports from subtropical areas of Mexico. We also compared the von Bertalanffy growth model with one proposed in this study for aquaculture purposes. The growth rate was higher during the first six months $\left(5.3 \mathrm{~mm} \mathrm{month}^{-1}\right)$ and then decreased to $3 \mathrm{~mm} \mathrm{month}{ }^{-1}$ until juveniles reached a size of $60 \mathrm{~mm}$ in one year. Growth rates were higher in February and lower in July through September. Both models described well the growth of P. sterna, but the adjustment and the estimation of parameters was better with the proposed model. Gametogenesis started in December 2009 at $50.9 \mathrm{~mm}$ (males) and $59.5 \mathrm{~mm}$ (females); gonad development occurred continuously throughout the year with a peak in February-March $\left(\sim 25-26^{\circ} \mathrm{C} ; 2.8 \mu \mathrm{g} \mathrm{L} \mathrm{L}^{-1}\right.$ chlorophyll $a$ concentration), when the gonad index was highest and oocytes were larger. When compared to other studies conducted in subtropical areas, the species uses different strategies to channel available energy into growth and reproduction in tropical regions; P. sterna grows quickly in Bahía de Acapulco and may obtain the size necessary for grafting (70-80 mm shell height) in 15-17 months.
\end{abstract}

Key words: Pteria sterna, growth, reproduction, Bahía de Acapulco, pearl cultivation.

RESUMEN. La concha nácar Pteria sterna sostiene una creciente industria perlera en la región subtropical del noroeste de México. En ambientes tropicales del país, el cultivo de perlas puede ser redituable, pero la poca información sobre la biología y ecología de la especie limita la definición de protocolos para la creación de granjas perleras. Se determinó el crecimiento absoluto, la tasa de crecimiento, los estadios reproductivos, los cambios en la talla de ovocitos y la talla de primera madurez de juveniles de P. sterna cultivados en la bahía de Acapulco durante el ciclo anual 2009-2010, y se comparó su respuesta en esta área tropical con registros de la especie para otras áreas subtropicales de México. Se comparó el modelo de crecimiento de von Bertalanffy con uno propuesto en este estudio para fines acuaculturales. La tasa de crecimiento fue mayor durante los primeros seis meses $\left(5.3 \mathrm{~mm} \mathrm{mes}^{-1}\right)$ y disminuyó a $3 \mathrm{~mm} \mathrm{mes}{ }^{-1}$ hasta que los juveniles alcanzaron la talla de $60 \mathrm{~mm}$ en un año. El crecimiento fue máximo en febrero y mínimo de julio a septiembre. Ambos modelos describieron bien el crecimiento de P. sterna, pero el ajuste y la estimación de los parámetros fue mejor con el modelo propuesto. La gametogénesis inició en diciembre de 2009 a una talla de $50.9 \mathrm{~mm}$ en los machos y $59.5 \mathrm{~mm}$ en las hembras; el desarrollo de la gónada fue continuo el resto del año, con un pico de desove en febrero-marzo $\left(\sim 25-26^{\circ} \mathrm{C} ; 2.8 \mu \mathrm{g} \mathrm{L}{ }^{-1}\right.$ de clorofila $\left.a\right)$ que coincidió con el máximo del índice gonádico y la mayor talla de los ovocitos. En comparación con ambientes subtropicales, la especie utiliza una estrategia diferente para el manejo de la energía para el crecimiento y reproducción en un ambiente tropical; en la bahía de Acapulco P. sterna puede alcanzar la talla optima de injerto para producción de perlas (70-80 mm de altura de la concha) en 15-17 meses.

Palabras clave: Pteria sterna, crecimiento, reproducción, bahía de Acapulco, cultivo de perlas. 


\section{INTRODUCTION}

Pearl production is a well-established and profitable industry that provides jobs and income to entire families and communities (Taylor and Strack 2008). Pearling activities have played a major role in the socioeconomic and cultural development of several countries in Asia and the South Pacific (Fong 2005). In Mexico, the presence of pearl oysters and pearls motivated the colonization of the Baja California Peninsula in the 16th century and contributed to the region's subsequent social and economic development (McLaurin-Moreno and Arizmendi-Castillo 2002, Cariño and Monteforte 1995). Nowadays, pearl farming in Mexico is a growing activity that mainly relies on the cultivation of the winged pearl oyster, Pteria sterna (Gould 1851) (McLaurinMoreno et al. 1997, Ruíz-Rubio et al. 2006). This species produces multicolored, high-quality pearls that are valuable in the international market (Kiefert et al. 2004); however, recurring problems associated with ensuring wild-collected or hatchery-reared spat continue to limit the availability of oysters for grafting operations and industry expansion.

Pteria sterna is distributed over a wide range of tropical and subtropical areas of the eastern Pacific coast, from the state of Baja California in northwestern Mexico to Peru (Keen 1971). In Mexico, particularly in its subtropical range in the Gulf of California, the species has been well studied for some of the key factors influencing the production of pearl farms. This includes field culturing methods (Monteforte 2013), development and growth (BückleRamírez et al. 1992, Saucedo and Monteforte 1997a, Martínez-Fernández et al. 2004), and reproduction (Saucedo and Monteforte 1997b, Vite-García and Saucedo 2008, Cáceres-Puig et al. 2009). These studies show that, compared with other pearl oyster species that breed in summer when water temperature increases and primary productivity decreases, $P$. sterna breeds between winter and spring when water temperature declines and productivity increases. The ecophysiological implications of this differential response are currently under investigation (González-Jiménez 2013).

In contrast, studies related to field cultivation, growth, and reproduction of $P$. sterna are scarce at other sites in the tropics, where the species is also present. In Bahía de Acapulco, Guerrero, Mexico, these studies include the seasonal collection of spat in artificial collectors (Torres-Zepeda et al. 2002) and growth and survival of juveniles held in suspended culture (Cantú-Cantú 2003). The studies show that $P$. sterna spatfall is recurrent throughout the year and is well adapted to the conditions of Bahía de Acapulco, which offers an opportunity to increase production through aquaculture programs. Pearl cultivation in Acapulco and on the Pacific coast of Mexico may be a profitable activity that aligns well with key economic and productive activities of the region, such as the elaboration of jewelry and ecotourism. Thus, further studies on baseline aspects of the biology and ecology of the species are essential.

\section{INTRODUCCIÓN}

La perlicultura (cultivo de perlas) es una industria bien establecida y redituable que proporciona trabajo e ingreso a familias y comunidades enteras (Taylor y Strack 2008). Esta actividad ha contribuido de forma significativa al desarrollo socioeconómico y cultural de numerosos países de Asia y en el Pacífico Sur (Fong 2005). En México, la presencia de ostras perleras y perlas motivó la colonización de la península de Baja California en el siglo XVI y promovió su posterior desarrollo social y económico (McLaurin-Moreno y Arizmendi-Castillo 2002, Cariño y Monteforte 1995). Hoy en día, la producción de perlas en México es una actividad creciente que depende principalmente de una especie: la concha nácar alada, Pteria sterna (Gould 1851), (McLaurin-Moreno et al. 1997, Ruíz-Rubio et al. 2006). Esta especie produce perlas multicolor de alta calidad y muy valoradas en el mercado internacional (Kiefert et al. 2004). Sin embargo, los problemas recurrentes para el aseguramiento de semilla vía la recolecta con colectores artificiales o su producción de forma controlada en laboratorio han limitado la disponibilidad continua y suficiente de ostras para las operaciones de perlicultura y el crecimiento de la industria.

Pteria sterna se distribuye a lo largo de un amplio margen de línea costera tropical y subtropical en el océano Pacífico oriental, desde el estado de Baja California, México, hasta Perú (Keen 1971). En el golfo de California, donde el intervalo de distribución de la especie es subtropical, se han estudiado algunos de los factores principales que influencian la producción de perlas, incluyendo los métodos de cultivo en campo (Monteforte 2013), el desarrollo y crecimiento de juveniles y adultos (Bückle-Ramírez et al. 1992, Saucedo y Monteforte 1997a, Martínez-Fernández et al. 2004) y la reproducción (Saucedo y Monteforte 1997b, Vite-García y Saucedo 2008, Cáceres-Puig et al. 2009). En general, estos estudios muestran que, en comparación con otras especies de ostras perleras que se reproducen en verano cuando la temperatura del agua se incrementa y la productividad primaria disminuye, P. sterna se reproduce entre invierno y primavera cuando la temperatura del agua disminuye y la productividad primaria aumenta. Las implicaciones ecofisiológicas de este tipo de regulación y respuesta diferencial aún se están investigando (González-Jiménez 2013).

Los estudios relacionados con el cultivo en campo, el crecimiento y la reproducción de $P$. sterna en otros sitios de distribución tropical donde la especie también está presente son muy escasos. En la bahía de Acapulco, estado de Guerrero, México, se ha evaluado la recolecta estacional de semilla en campo (Torres-Zepeda et al. 2002) y el crecimiento y la supervivencia de juveniles en cultivo en suspensión (Cantú-Cantú 2003). Los estudios demuestran que el reclutamiento de semilla de $P$. sterna es continuo casi todo el año y que la especie está bien adaptada a las condiciones de la bahía de Acapulco, lo cual ofrece la oportunidad de incrementar la producción mediante programas de acuicultura. 
Here, we report on the absolute growth, growth rate, gonad development, changes in oocyte size, and size at first maturity of juvenile $P$. sterna under suspended cultivation in Bahía de Acapulco over one annual cycle (2009-2010). The main objective is to compare the response of the oysters in this tropical location with reports on the species at other subtropical sites in the Gulf of California. Considering that growth models are reliable tools for detecting the age/size at which animals can be used for culturing pearls (Sims 1994), the second objective is to compare the classical von Bertalanffy growth model with one proposed here that has aquaculture applications.

\section{MATERIALS AND METHODS}

\section{Origin of oysters and experimental design}

This study was conducted in Bahía de Acapulco $\left(16^{\circ} 50^{\prime} \mathrm{N}, 99^{\circ} 54^{\prime} \mathrm{W}\right)$. The area has a tropical climate, warmhumid conditions, and cold bottom currents that promote phytoplankton blooms and favor high productivity most of the year (Cantú-Cantú 2003).

In May 2009, wild pearl oyster spat were recruited from a collection system operated by the Universidad Autónoma de Guerrero. The system consisted of a stationary research vessel from which a set of vertical lines were hung. Either artificial collectors or culture devices were attached to each vertical line.

In July 2009, after the spatfall, 2-month-old juveniles $(13.2 \pm 0.52 \mathrm{~mm}$ shell height SE; $0.75 \pm 0.074 \mathrm{~g} \mathrm{SE})$ were transferred to Nestier culture trays $\left(50 \times 50 \times 10 \mathrm{~cm} ; 10 \mathrm{~mm}^{2}\right.$ pore size). Culture trays were organized in three groups or replicate stacks hung from the vessel's vertical lines at $12 \mathrm{~m}$ depth. Each replicate stack had four levels of Nestier trays, and each tray held an equal number of oysters, with a stocking density of 100 oysters per tray the first two months, 75 oysters per tray the third month, and 50 oysters per tray in subsequent months (Monteforte et al. 2005). The first two months, oysters were placed in mesh bags $\left(1 \mathrm{~mm}^{2}\right.$ pore size $)$ inside the Nestier trays to prevent the loss of small juveniles; the mesh was removed on the third month when oysters reached $\sim 20 \mathrm{~mm}$. We also adopted a repositioning protocol to maintain a constant density in the Nestier culture trays throughout the study (Monteforte et al. 2005). For this, dead oysters were removed monthly and replaced with live oysters taken from replicate stacks kept under the same conditions as the experimental stacks. During the grow-out phase, water temperature $\left( \pm 0.1^{\circ} \mathrm{C}\right)$ and chlorophyll $a( \pm 0.1 \mu \mathrm{g} \mathrm{L}-1)$ content were recorded on a monthly basis at the same depth as the trays using a portable meter (YSI model 6920, Yellow Springs, $\mathrm{OH})$.

\section{Absolute growth and growth rate}

Each month during the annual cycle, 30 juvenile oysters were randomly selected from the Nestier culture trays,
El cultivo de perlas en Acapulco y la costa del Pacífico en México puede ser una actividad rentable que se alinea bien con las principales actividades económicas de la región, como la producción de joyería y el ecoturismo. Para ello, es necesario realizar estudios de base sobre la biología y ecología de la especie.

En el presente trabajo se estudiaron el crecimiento absoluto, la tasa de crecimiento, el desarrollo gonadal, los cambios en la talla de ovocitos y la talla de primera madurez de juveniles de $P$. sterna en condiciones de cultivo en suspensión en la bahía de Acapulco durante un ciclo anual (2009-2010). El objetivo principal fue comparar la respuesta de las ostras en este ambiente tropical con los reportes previos de la especie en otros sitios subtropicales del golfo de California. Considerando que los modelos de crecimiento proporcionan herramientas útiles para entender la adecuación de las ostras para la perlicultura (Sims 1994), también se propuso comparar el modelo clásico de crecimiento de von Bertalanffy con uno desarrollado en este estudio que tiene aplicaciones para la acuicultura.

\section{MATERIALES Y MÉTODOS}

\section{Origen de las ostras y diseño experimental}

El presente estudio se llevó a cabo en la bahía de Acapulco $\left(16^{\circ} 50^{\prime} \mathrm{N}, 99^{\circ} 54^{\prime} \mathrm{W}\right)$, donde el clima es tropical, el aire cálido y subhúmedo, y el mar presenta corrientes frías de fondo que permiten un florecimiento continuo de fitoplancton para promover una alta productividad la mayor parte del año (Cantú-Cantú 2003).

En mayo de 2009, una generación de semillas silvestres fue reclutada mediante un sistema operado por la Universidad Autónoma de Guerrero. El sistema estuvo formado por un buque de investigación estacionario, del cual se colgaron una serie de líneas verticales de recolecta. En cada línea se colocaron ya sea colectores artificiales o estructuras de cultivo.

En julio de 2009, una vez finalizada la recolecta, los juveniles de dos meses de edad (13.2 $\pm 0.52 \mathrm{~mm}$ de altura de la concha SE; $0.75 \pm 0.074 \mathrm{~g} \mathrm{SE}$ ) fueron transferidos a canastas de cultivo tipo Nestier $\left(50 \times 50 \times 10 \mathrm{~cm} ; 10 \mathrm{~mm}^{2} \mathrm{de}\right.$ apertura de poro). Las canastas Nestier fueron organizadas en tres grupos o lotes replicados, los cuales se colgaron de las líneas verticales del buque de investigación, a una profundidad de $12 \mathrm{~m}$. Cada lote de cultivo tenía a su vez cuatro niveles de canastas Nestier, y cada nivel el mismo número de ostras sembradas a una densidad constante: 100 ostras por nivel durante los primeros dos meses, 75 ostras por nivel el tercer mes, y 50 ostras por nivel en los meses subsiguientes (Monteforte et al. 2005). En los primeros dos meses, las ostras fueron colocadas en mallas plásticas $\left(1 \mathrm{~mm}^{2}\right.$ de luz de malla) dentro de las canastas Nestier para prevenir la pérdida de juveniles de talla pequeña; la malla fue retirada el tercer mes cuando las ostras alcanzaron $\sim 20 \mathrm{~mm}$ de altura de la 
measured for shell height (nearest $0.1 \mathrm{~mm}$ ), weighed for whole wet weight with shell (nearest $0.1 \mathrm{~g}$ ), and preserved in a solution of $10 \%$ formaldehyde for $48 \mathrm{~h}$. The oysters were then rinsed and removed from their shells, and samples of gonad tissue were extracted and preserved in $70 \%$ ethanol to determine gonad stages.

Absolute growth and growth rates were determined from monthly shell height and soft tissue wet weight data (Saucedo et al. 1998). To calculate growth rates (in mm month ${ }^{-1}$ and $\mathrm{g} \mathrm{month}^{-1}$ ), the difference between the final and initial sizes was divided by the cultivation time (in months).

\section{Growth models}

We evaluated two models to compare the growth in size of juveniles cultivated in Bahía de Acapulco. The first one represents a modification of the model proposed by Ratkoswsky (1986), which considers that the time intervals are the same, the initial time is zero, and there is only one growth datum at each time interval. For aquaculture applications, the model also incorporates the duration of the cultivation period $(c)$. Details of the proposed model can be found in Hernández-Llamas and Ratkowsky (2004) and Ruíz-Velazco et al. (2010):

$$
L_{t}=L_{i}+\left(L_{f}-L_{i}\right)\left(\frac{1-k^{t}}{1-k^{c}}\right)
$$

where $L_{i}$ and $L_{f}$ are the initial and final shell heights, $k$ is the rate at which $L$ changes, and $t$ is the time.

Our results were compared to those obtained with the classical von Bertalanffy growth model:

$$
L_{t}=L_{\infty}\left(1-e^{-k\left(t-t_{0}\right)}\right)
$$

where $L_{\infty}$ is the asymptotic growth, $k$ is a constant, and $t_{0}$ is the time when the initial growth is zero.

For the adjustment of both models, the sum of residual squares, ease of convergence, and biological interpretation of parameters were compared (Ratkowsky 1986, HernándezLlamas and Ratkowsky 2004). We evaluated a set of 14 cases representative of individual growth.

\section{Reproduction}

Preserved gonad samples were dehydrated, embedded in Paraplast X-tra (SPI Supplies, West Chester, PA), and thinsectioned to 3-4 $\mu \mathrm{m}$ along the anterior-posterior axis (Kim et al. 2006). Samples were stained with hematoxylin and eosin, and studied under a light microscope at $10 \times$ and $40 \times$ magnification to identify five stages of gonad development (undifferentiated, developing, ripe, spawning, and spent) and gender (undifferentiated, female, and male) to determine the sex ratio (Saucedo and Monteforte 1997b). concha. Se adoptó un protocolo de reposición de ostras para mantener constante la densidad de siembra en las canastas Nestier a lo largo del estudio (Monteforte et al. 2005). Para ello, las ostras muertas fueron removidas y repuestas cada mes por ostras vivas tomadas de los lotes de réplica mantenidos bajo las mismas condiciones de cultivo que los lotes experimentales. Durante la fase de engorda, se registraron los cambios estacionales en la temperatura del agua $\left( \pm 0.1^{\circ} \mathrm{C}\right)$ y la concentración de clorofila $a\left( \pm 0.1 \mu \mathrm{g} \mathrm{L}^{-1}\right)$ mensualmente a la misma profundidad de cultivo $(12 \mathrm{~m})$ utilizando una sonda portátil (YSI modelo 6920, Yellow Springs, OH).

\section{Crecimiento absoluto y tasa de crecimiento}

Cada mes durante el ciclo anual, 30 juveniles de ostra seleccionados aleatoriamente de cada lote de canastas Nestier fueron medidos para registrar la altura de la concha $(0.1 \mathrm{~mm})$, pesados para obtener el peso fresco total con concha $(0.1 \mathrm{~g})$ y preservados en una solución de formaldehido al $10 \%$ por $48 \mathrm{~h}$. Transcurrido este tiempo, los juveniles fueron enjuagados y removidos de la concha, y se tomaron muestras del tejido gonadal, las cuales se preservaron en etanol al $70 \%$ para determinar los estadios de desarrollo gonadal.

El crecimiento absoluto y la tasa de crecimiento fueron determinados a partir de los datos mensuales de altura de la concha y peso fresco total de las ostras (Saucedo et al. 1998). Para calcular la tasa de crecimiento (en mm mes ${ }^{-1} \mathrm{y} \mathrm{g} \mathrm{mes}^{-1}$ ), la diferencia entre las tallas final e inicial fue dividida entre el tiempo de cultivo (en meses).

\section{Modelos de crecimiento}

Se evaluaron dos modelos para comparar el crecimiento en talla (altura) de los juveniles de P. sterna en la bahía de Acapulco. El primero representó una modificación del modelo de Ratkowsky (1986), el cual considera que los intervalos de tiempo son iguales, el tiempo inicial es cero y solo existe un dato de crecimiento para cada intervalo de tiempo. Para su aplicación en acuicultura, el modelo también incorpora la duración del periodo de cultivo (c). Los detalles del modelo propuesto pueden ser consultados en HernándezLlamas y Ratkowsky (2004) y Ruíz-Velazco et al. (2010).

$$
L_{t}=L_{i}+\left(L_{f}-L_{i}\right)\left(\frac{1-k^{t}}{1-k^{c}}\right)
$$

donde $L_{i}$ y $L_{f}$ son las tallas (alturas) inicial y final, $k$ es la tasa a la cual cambia estacionalmente $L$, y $t$ es el tiempo.

Los resultados del modelo propuesto fueron comparados con los resultados obtenidos con el modelo clásico de crecimiento de von Bertalanffy:

$$
L_{t}=L_{\infty}\left(1-e^{-k\left(t-t_{0}\right)}\right)
$$


Since pearl oysters have diffuse gonads, a gonad index was calculated assigning numerical categories to each development stage: $0=$ undifferentiated or spent, $1=$ developing, 2 = ripe, and 3 = spawning (Heffernan et al. 1989). Then, the gonad index (GI) formula was applied:

$$
\mathrm{GI}=n_{2}+3 n_{3}+2 n_{4} / N
$$

In the formula, the number of oysters $(n)$ in each category was multiplied by the numerical value assigned to each reproductive stage $(2,3,4)$.

Seasonal changes in oocyte size were measured following Grant and Tyler (1983). Thirty complete oocytes in three random areas of the ovary were photographed and processed with Image Pro Plus (v6.0, Media Cybernetics, Bethesda, $\mathrm{MD})$ to calculate their mean diameter $(\mu \mathrm{m})$. Only nearripe (vitellogenic) and ripe (postvitellogenic) oocytes were considered.

Size at first maturity was determined assuming that all oysters in the study came from the same cohort and that their sizes were homogeneous. Thus, size/age at first maturity is the moment when $50 \%$ of the cultivated population reached the ripe stage (Campbell and Ming 2003).

\section{Statistical treatment of data}

The values of initial juvenile size were analyzed for group normality with the Kolmogorov-Smirnov test and for homogeneity of variances with the Levene test (Sokal and Rohlf 1981). For both models (von Bertalanffy and the proposed model), data were adjusted and parameters were estimated by non-linear regression using Statistica (StatSoft v8.0, Tulsa, OK). Correlation analyses were applied to determine the relationships between growth rates and environmental parameters. One-way ANOVA was used to detect significant differences in the gonad index and oocyte diameter over time. As needed, post hoc mean comparisons using the Tukey test were used. The level of significance was set at $P<0.05$ for all analyses.

\section{RESULTS}

\section{Seasonal changes in water temperature and chlorophyll $a$ levels}

Water temperature varied $5{ }^{\circ} \mathrm{C}$ throughout the year; it was highest $\left(\sim 30^{\circ} \mathrm{C}\right)$ from August to October 2009 and lowest $\left(\sim 25^{\circ} \mathrm{C}\right)$ from March to May 2010. In contrast, there were marked changes in chlorophyll $a$ content; the highest concentration occurred in June $2010\left(7.1 \mu \mathrm{g} \mathrm{L}^{-1}\right)$ and the lowest in July $\left(0.5 \mu \mathrm{g} \mathrm{L}^{-1}\right)$ and October $2009\left(0.9 \mu \mathrm{g} \mathrm{L}^{-1}\right)$.

\section{Absolute growth and growth rate}

Average increase in shell height was $46.9 \mathrm{~mm}$, from the start of the trials in July $2009(13.2 \mathrm{~mm})$ to the end in June donde $L_{\infty}$ es el crecimiento asintótico, $k$ es una constante, y $t_{0}$ es el tiempo al cual el crecimiento inicial es cero.

Para el ajuste de ambos modelos, se compararon como variables de respuesta la suma de cuadrados residuales, la facilidad de convergencia y la interpretación biológica de los parámetros de crecimiento (Ratkowsky 1986, HernándezLlamas y Ratkowsky 2004). Esto se evaluó en una muestra de 14 datos representativos del crecimiento individual.

\section{Reproducción}

Las muestras de tejido gonadal preservadas fueron deshidratadas, incluidas en Paraplast X-tra (SPI Supplies, West Chester, PA) y seccionadas con un micrótomo a 3-4 $\mu \mathrm{m}$ a lo largo del eje antero-posterior del cuerpo (Kim et al. 2006). Posteriormente, las muestras fueron teñidas con hematoxilina-eosina y analizadas bajo un microscopio óptico a $10 \times$ y $40 \times$ de aumento para caracterizar el ciclo reproductivo a partir de cinco estadios básicos (indiferenciado, desarrollo, maduro, desove y postdesove). Se identificó el sexo dominante (indiferenciado, hembra y macho) y se calculó la proporción sexual (Saucedo y Monteforte 1997b).

Dado que las ostras perleras tienen gónadas difusas, se calculó un índice gonádico asignando categorías numéricas a cada estadio de desarrollo: 0 = indiferenciado o postdesove; $1=$ en desarrollo; 2 = maduro, y $3=$ desove (Heffernan et al . 1989). Con estos datos, se aplicó la fórmula del índice gonádico (IG):

$$
\mathrm{IG}=n_{2}+3 n_{3}+2 n_{4} / N
$$

En la fórmula, el número de ostras $(n)$ en cada estadio se multiplicó por el valor numérico asignado a cada estadio reproductivo $(2,3,4)$.

Los cambios estacionales en la talla de los ovocitos se determinaron de acuerdo con lo propuesto por Grant y Tyler (1983). Treinta ovocitos completos seleccionados en tres campos aleatorios del ovario fueron fotografiados y procesados en la computadora con el programa Image Pro Plus (v6.0, Media Cybernetics, Bethesda, MD) para calcular su diámetro promedio $(\mu \mathrm{m})$. Sólo los ovocitos en estadios avanzados de desarrollo (vitelogénicos) y maduros (postvitelogénicos) se consideraron para el análisis.

La talla de primera madurez se determinó bajo el supuesto de que todas las ostras jóvenes de este estudio provinieron de la misma cohorte $\mathrm{y}$, por tanto, sus tallas promedio eran homogéneas. Con base en esto, la talla/edad de primera madurez representó el momento en que el 50\% de la población en cultivo alcanzó el estadio de madurez sexual (Campbell y Ming 2003).

\section{Tratamiento estadístico de datos}

Los valores de talla inicial de juveniles fueron analizados para determinar la normalidad de los datos con la prueba de 
$2010(60.1 \mathrm{~mm})$. The growth trend was pronounced during the first six months, leveled, and then decreased slightly in May-June 2010, indicating an asymptote (fig. 1a).

The increase in total wet weight (with shell) was $37.2 \mathrm{~g}$ from July $2009(0.75 \mathrm{~g})$ to June $2010(37.9 \mathrm{~g})$. The growth trend was marked during the first six months and decreased in subsequent months; the data show no evidence of an asymptote (fig. 1b).

The growth rate, measured as shell height, was highest in February 2010 (7.65 mm month $\left.{ }^{-1}\right)$ and lowest in May 2010 $\left(0.7 \mathrm{~mm} \mathrm{month}^{-1}\right)$; the mean annual growth rate was $4.27 \mathrm{~mm}$ month $^{-1}$ (fig. 2a). The growth rate, measured as wet tissue biomass, was highest in February $\left(7.57 \mathrm{~g} \mathrm{month}^{-1}\right)$ and lowest in July $2010\left(0.47 \mathrm{~g} \mathrm{month}^{-1}\right)$; the annual mean growth rate was 3.38 g month $^{-1}$ (fig. 2b).

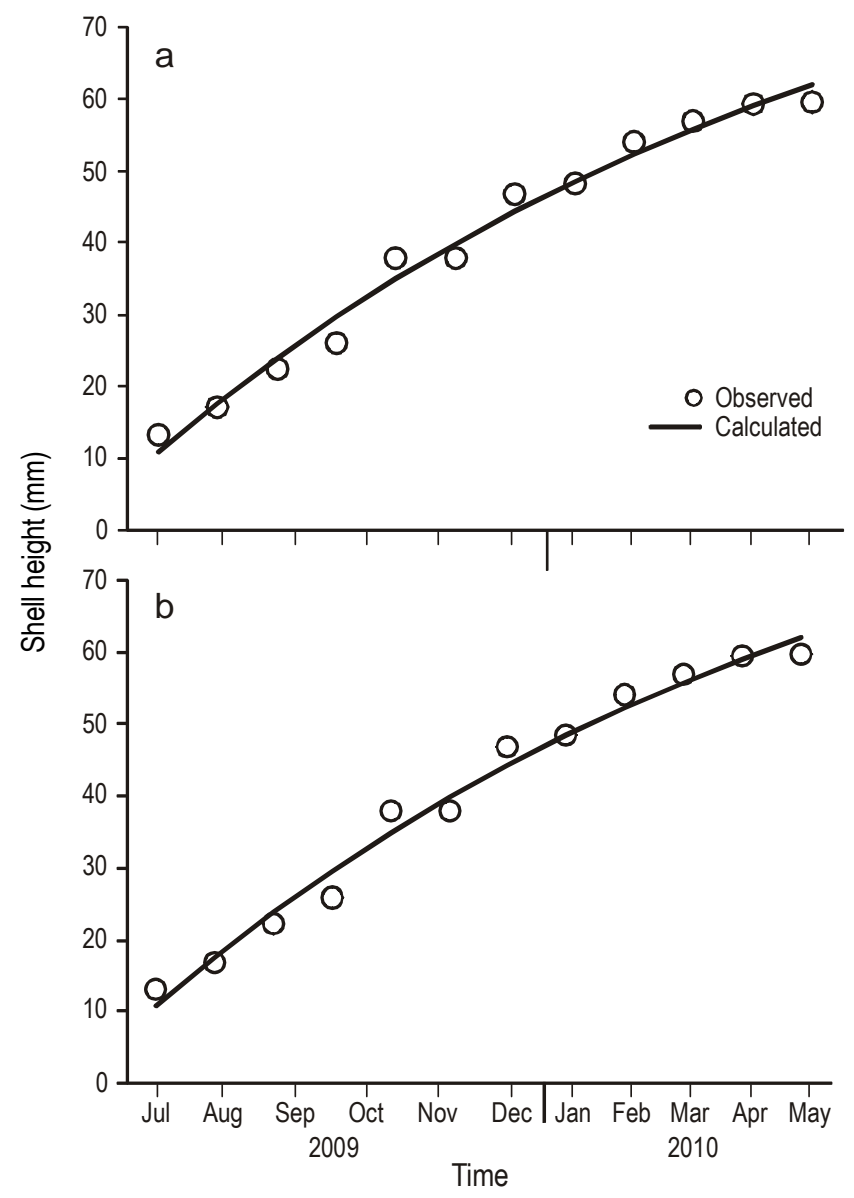

Figure 1. Data fit to (a) our proposed model and (b) the von Bertalanffy model to describe growth in shell height of the winged pearl oyster, Pteria sterna, cultivated under suspension conditions in Bahía de Acapulco (Mexico) over one annual cycle.

Figura 1. Ajuste de datos al (a) modelo propuesto en este estudio y (b) modelo de von Bertalanffy para describir el crecimiento en altura de la concha nácar, Pteria sterna, mantenida bajo condiciones de cultivo en suspensión en la bahía de Acapulco (México) durante un ciclo anual.
Kolmogorov-Smirnov y la homogeneidad de varianzas con la prueba de Levene (Sokal y Rohlf 1981). Para ambos modelos (von Bertalanffy y el propuesto en este estudio), el ajuste de datos y la estimación de parámetros se realizó mediante un análisis de regresión no lineal utilizando Statistica (StatSoft v8.0, Tulsa, OK). Se corrieron análisis de correlación para determinar la relación entre las tasas de crecimiento y los parámetros ambientales. Se realizaron análisis de varianza de una vía para detectar diferencias significativas en el índice gonádico y la talla de ovocitos en función del tiempo. Según se requirió, se aplicaron comparaciones a posteriori de medias con la prueba de Tukey. El nivel de significancia de todas las pruebas se determinó a $P<0.05$.

\section{RESULTADOS}

\section{Cambios estacionales en la temperatura del agua y concentración de clorofila $a$}

La temperatura del agua varió $5{ }^{\circ} \mathrm{C}$ durante el ciclo anual; el valor máximo $\left(\sim 30^{\circ} \mathrm{C}\right)$ se registró entre agosto y octubre de 2009 y el mínimo $\left(\sim 25^{\circ} \mathrm{C}\right)$, entre marzo y mayo de 2010 . Los cambios en la concentración de clorofila $a$ fueron más marcados; el valor máximo se resgistró en junio de 2010 $\left(7.1 \mu \mathrm{g} \mathrm{L}^{-1}\right)$ y el mínimo en julio $\left(0.5 \mu \mathrm{g} \mathrm{L}^{-1}\right)$ y octubre $\left(0.9 \mu \mathrm{g} \mathrm{L}^{-1}\right)$ de 2009.

\section{Crecimiento absoluto y tasa de crecimiento}

El incremento total en la altura de la concha fue de $46.9 \mu \mathrm{m}$, desde el inicio del experimento en julio de 2009 $(13.2 \mathrm{~mm})$ hasta el final en junio de $2010(60.1 \mathrm{~mm})$. El patrón de incremento fue pronunciado durante los primeros seis meses y luego se niveló y disminuyó hacia mayo-junio de 2010, lo cual sugiere una asíntota (fig. 1a).

El incremento en el peso fresco total (con concha) fue de $37.2 \mathrm{~g}$, desde julio de 2009 (0.75 g) hasta junio de 2010 $(37.9 \mathrm{~g})$. El incremento también fue marcado los primeros seis meses y decreció gradualmente en los meses subsecuentes, pero los datos no indicaron una asíntota (fig. 1b).

La tasa de crecimiento en altura de la concha fue mayor en febrero de 2010 ( $\left.7.65 \mathrm{~mm} \mathrm{mes}^{-1}\right)$ y menor en mayo de $2010\left(0.7 \mathrm{~mm} \mathrm{mes}^{-1}\right)$; la tasa de crecimiento promedio fue de $4.27 \mathrm{~mm} \mathrm{mes}^{-1}$ para todo el ciclo anual (fig. 2a). La tasa de crecimiento en peso fresco fue mayor en febrero ( $\left.7.57 \mathrm{~g} \mathrm{mes}^{-1}\right)$ y menor en julio $\left(0.47 \mathrm{~g} \mathrm{mes}^{-1}\right)$ de 2010 ; la tasa de crecimiento promedio fue de $3.38 \mathrm{~g} \mathrm{mes}^{-1}$ para el ciclo anual (fig. 2b).

La relación entre la tasa de crecimiento y la temperatura del agua fue significativa y negativa $(P<0.05 ; r=-0.62)$. Por el contrario, la relación entre la tasa de crecimiento y la concentración de clorofila $a$ no fue significativa $(P>0.05$; $r=0.26)$. 
The relationship between growth rate and water temperature was significant $(P<0.05)$ and negative $(r=-0.62)$; however, the relationship between growth rate and chlorophyll $a$ levels was not significant $(P>0.05 ; r=0.26)$.

\section{Growth models}

Both our proposed model (fig. 1a) and the von Bertalanffy model (fig. 1b) significantly fit the growth (shell height) data $(P<0.05)$. However, when compared to our proposed model, the von Bertalanffy model showed no convergence of the initial values and a disproportion of the values of fitted parameters for cases 8,9 , and 12, which were not comparable to the other cases (table 1).

The sum of residual squares was similar in both cases, but our model provided lower values than the von Bertalanffy model (table 1), suggesting a better fit to the growth of P. sterna under suspension conditions in Bahía de Acapulco.

\section{Reproduction}

The histological analysis of gonads revealed that juveniles were sexually inactive from July through November 2009 (fig. 3a). Gonads started developing in December 2009,

\section{Modelos de crecimiento}

Tanto el modelo propuesto en este estudio (fig. 1a) como el de von Bertalanffy (fig. 1b) se ajustaron significativamente $(P<0.05)$ a los datos de crecimiento (altura de la concha). Sin embargo, en comparación con el modelo propuesto, el modelo de von Bertalanffy careció de convergencia de los valores iniciales y mostró una desproporción de los valores en los parámetros estimados para los datos 8,9 , y 12, los cuales no fueron comparables con los otros casos (tabla 1).

La suma de cuadrados residuales fue similar con ambos modelos, pero el modelo propuesto generó valores más pequeños que el modelo de von Bertalanffy (tabla 1), sugiriendo un mejor ajuste para el crecimiento de $P$. sterna bajo las condiciones de cultivo en suspensión en la bahía de Acapulco.

\section{Reproducción}

Según el análisis histológico, los juveniles estuvieron sexualmente inactivos de julio a noviembre de 2009 (fig. 3a). Las gónadas comenzaron a desarrollarse en diciembre de 2009 , pero sólo en un $7 \%$ de la población muestreada. El desarrollo de los gametos fue continuo de enero a junio de

Table 1. Fit parameters and sum of residual squares (SRS) of the regression of two growth models describing the growth of the winged pearl oyster, Pteria sterna, cultivated under suspension conditions in Bahía de Acapulco (Mexico) over one annual cycle. $L_{\infty}$, asymptotic growth; $K$, rate at which $L$ changes (constant); $t_{0}$, time when initial growth is zero; $L_{0}$, initial shell height; $L_{f}$, final shell height.

Tabla 1. Parámetros de ajuste y suma de cuadrados residuales (SRS) de la regresión aplicada a los dos modelos que describen el crecimiento de la concha nácar, Pteria sterna, mantenida bajo condiciones de cultivo en suspensión en la bahía de Acapulco (México) durante un ciclo anual. $L_{\infty}$, crecimiento asintótico; $K$, tasa a la cual cambia $L$ (constante); $t_{0}$, tiempo al cual el crecimiento inicial es cero; $L_{0}$, altura inicial de la concha; $L_{f}$, altura final de la concha.

\begin{tabular}{|c|c|c|c|c|c|c|c|c|}
\hline \multirow[b]{2}{*}{ Case } & \multicolumn{4}{|c|}{ von Bertalanffy model } & \multicolumn{4}{|c|}{ Proposed model } \\
\hline & $L_{\infty}$ & K & $t_{0}$ & SRS & $L_{0}$ & $K$ & $L_{f}$ & SRS \\
\hline 1 & 7.0511 & 0.1250 & -1.7515 & 1.2847 & 1.3864 & 0.8820 & 5.7870 & 1.2847 \\
\hline 2 & 9.8627 & 0.0819 & -1.5340 & 5.1332 & 1.1652 & 0.9213 & 6.6097 & 5.1332 \\
\hline 3 & 43.2136 & 0.0128 & -2.5985 & 2.0588 & 1.4138 & 0.9873 & 7.3659 & 2.0588 \\
\hline 4 & 13.7430 & 0.0386 & -2.7696 & 4.5286 & 1.3959 & 0.9621 & 5.9802 & 4.5286 \\
\hline 5 & 72.8202 & 0.0065 & -2.8133 & 3.6861 & 1.3203 & 0.9937 & 6.6851 & 3.6861 \\
\hline 6 & 53.9360 & 0.0088 & -2.6660 & 6.1106 & 1.2635 & 0.9914 & 6.5908 & 6.1106 \\
\hline 7 & 33.6848 & 0.0164 & -2.2228 & 4.8643 & 1.2049 & 0.9837 & 7.0030 & 4.8643 \\
\hline 8 & 1722.0130 & 0.0002 & -4.0420 & 4.3919 & 1.7039 & 1.0238 & 6.5646 & 4.3629 \\
\hline 9 & 9402.3500 & 0.00005 & -2.1940 & 3.8970 & 1.4080 & 1.0494 & 8.0582 & 3.6677 \\
\hline 10 & 8.9106 & 0.0886 & -1.8369 & 4.2183 & 1.3390 & 0.9151 & 6.2973 & 4.2183 \\
\hline 11 & 10.4517 & 0.0541 & -2.1996 & 3.0884 & 1.1734 & 0.9473 & 5.6063 & 3.0884 \\
\hline 12 & 590.8122 & 0.0008 & -3.2419 & 3.3468 & 1.5248 & 1.0037 & 7.0776 & 3.3455 \\
\hline 13 & 9.9603 & 0.0679 & -1.7416 & 1.8610 & 1.1112 & 0.9343 & 6.0434 & 1.8610 \\
\hline 14 & 85.9449 & 0.0063 & -2.1268 & 1.7332 & 1.1519 & 0.9938 & 7.3657 & 1.7332 \\
\hline
\end{tabular}

Cases in bold represent lower SRS values 


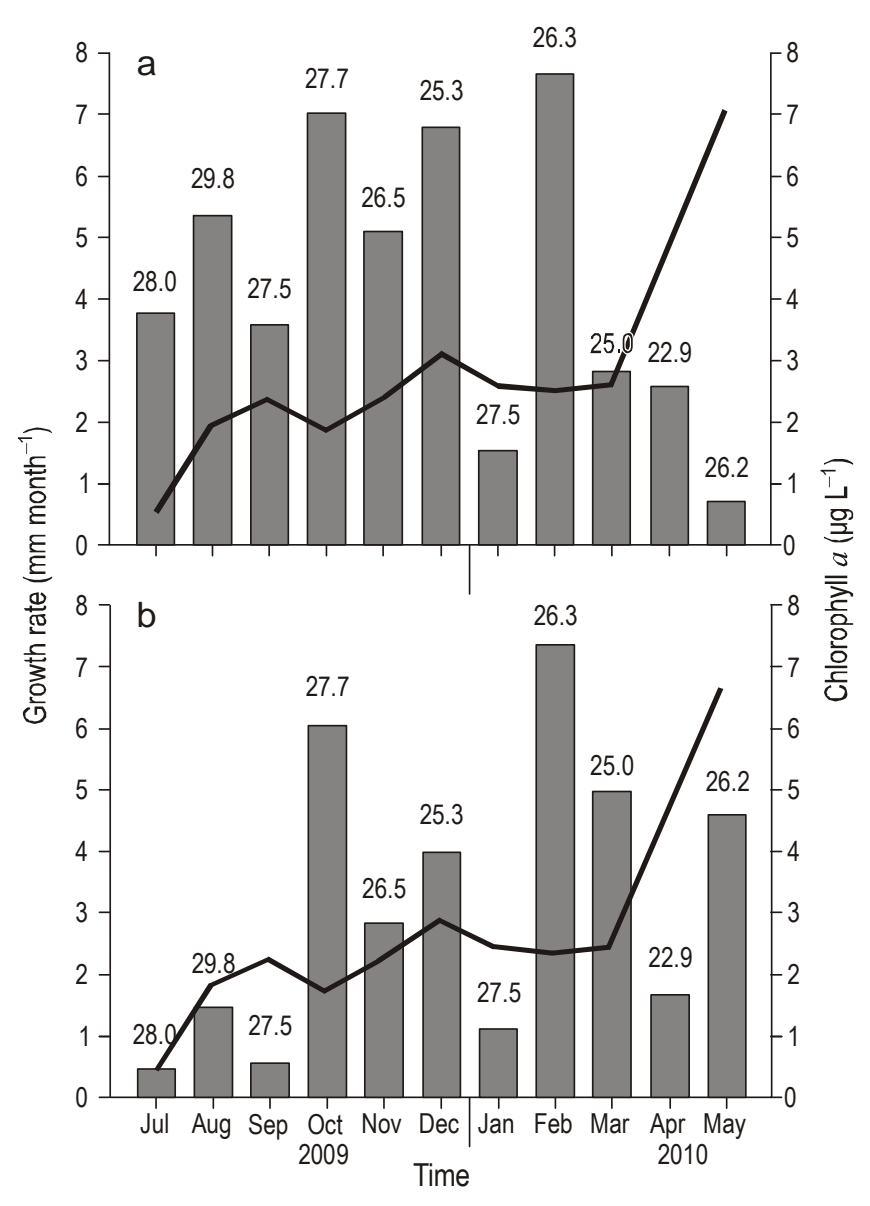

Figure 2. Growth rates in terms of (a) shell height and (b) wet weight of the winged pearl oyster, Pteria sterna, cultivated under suspension conditions in Bahía de Acapulco over one annual cycle. Values above the bars correspond to mean monthly water temperatures $\left({ }^{\circ} \mathrm{C}\right)$.

Figura 2. Tasas de crecimiento en (a) altura de la concha y (b) peso fresco total de la concha nácar, Pteria sterna, mantenida bajo condiciones de cultivo en suspensión en la bahía de Acapulco durante un ciclo anual. Los valores arriba de las barras corresponden a las temperaturas promedio del agua $\left({ }^{\circ} \mathrm{C}\right)$.

but only in $7 \%$ of the sample. From January through June 2010 , gonad growth was continuous $(\sim 35 \%)$ and reached a peak in ripeness in March 2010 (23\%). Spawning was also continuous from January (7\%) through June (21\%), with a peak in April 2010 (36\%). The spent stage occurred in December-January and April-June 2010 (7\% and 44\%, respectively).

Seasonal changes in oocyte size were significant $(P<$ $0.05)$. Maximum oocyte diameter was recorded in March $2010(39.8 \mu \mathrm{m})$ and minimum in June $2010(22.1 \mu \mathrm{m})$; the annual mean diameter was $32.4 \mu \mathrm{m}$ (fig. $3 \mathrm{~b}$ ).

Males outnumbered females during most of the cycle, yielding a female to male ratio of $0.59: 1$. Additionally, $6 \%$ of the sampled population corresponded to undifferentiated oysters and $3 \%$ to hermaphrodites.
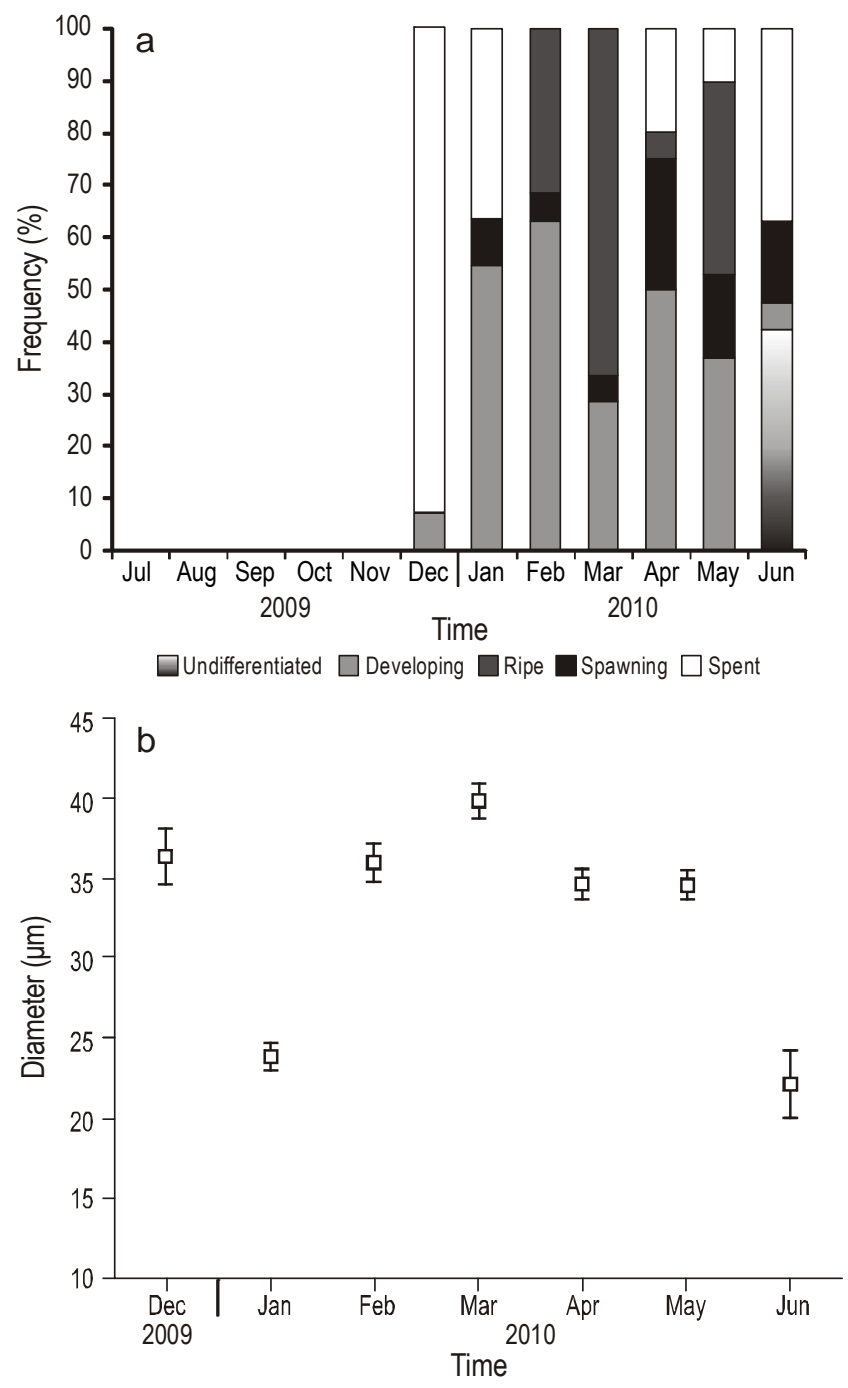

Figure 3. Seasonal changes in (a) gonad development stages and (b) oocyte diameter of the winged pearl oyster, Pteria sterna, cultivated under suspension conditions in Bahía de Acapulco over one annual cycle. The values shown in (b) are the mean (square) and standard error (bars).

Figura 3. Cambios estacionales en (a) los estadios de desarrollo gonadal y (b) el diámetro de los ovocitos de la concha nácar, Pteria sterna, mantenida bajo condiciones de cultivo en suspensión en la bahía de Acapulco durante un ciclo anual. Los valores en (b) reflejan la media (cuadro) y desviación estándar (barras).

$2010(\sim 35 \%)$ y alcanzó el pico de maduración en marzo de $2010(23 \%)$. El desove también fue continuo de enero (7\%) a junio (21\%), con un pico en abril (36\%) de 2010. El estadio de postdesove se presentó en diciembre-enero y abril-junio de 2010 ( $7 \%$ y $44 \%$, respectivamente).

Los cambios estacionales en el diámetro de los ovocitos fueron significativos $(P<0.05)$. Los valores máximos se registraron en marzo de $2010(39.8 \mu \mathrm{m})$ y los mínimos en junio de $2010(22.1 \mu \mathrm{m})$; el diámetro promedio para todo el ciclo anual fue de $32.4 \mu \mathrm{m}$ (fig. $3 \mathrm{~b}$ ). 
Seasonal variations in the gonad index were significant $(P<0.05)$, consistent with the changes in oocyte size, and reflected an inverse relationship with water temperature (fig. 4a) and chlorophyll $a$ content (fig. 4b). The gonad index was highest (37\%) in March $2010\left(25^{\circ} \mathrm{C} ; 2.25 \mu \mathrm{g} \mathrm{L}-1\right)$ and lowest (1\%) in December $2009\left(28^{\circ} \mathrm{C} ; 3.1 \mu \mathrm{g} \mathrm{L}^{-1}\right)$.

The cumulative frequency data of female and male sizes were significantly adjusted to a logistic model $(r=0.99)$, revealing that males became sexually mature at $50.9 \mathrm{~mm}$ shell height and females at $59.5 \mathrm{~mm}$ (fig. $5 \mathrm{a}, \mathrm{b}$ ).

\section{DISCUSSION}

Worldwide, most cultured pearls are produced in tropical regions of Asia and the South Pacific, mainly northern Australia, China, French Polynesia, Indonesia, and the Philippines (Taylor and Strack 2008). These countries cultivate mostly Pinctada species ( $P$. fucata, $P$. margaritifera, P. maxima), but the tropical winged pearl oyster, Pteria penguin, has gradually increased in value for the production of high-quality half pearls or mabé (Kishore et al. 2013). Similarly, P. sterna can be successfully cultured under tropical conditions, despite its preference for subtropical and temperate climates, and is thus a viable candidate for pearl cultivation along the eastern Pacific coast of Latin America, including Mexico.

Juvenile $P$. sterna grew rapidly in shell height from July through December 2009 (5.3 mm month $\left.{ }^{-1}\right)$. The growth rate declined by $41 \%$ from January through April $2010\left(3 \mathrm{~mm} \mathrm{month}^{-1}\right)$, in correspondence with the time when reproductive activity started (the gonad index increased and oocytes were larger). The growth trend yielded an inverse, negative relationship with water temperature, with maximum values in spring and minimum in summer. Our annual average growth rate $\left(4.27 \mathrm{~mm} \mathrm{month}^{-1}\right)$ is $\sim 20 \%$ greater than the maximum growth rate $\left(3.5 \mathrm{~mm}\right.$ month $\left.^{-1}\right)$ reported for juvenile P. sterna cultivated in Bahía de La Paz (southern Gulf of California) at an initial size of $42.9 \mathrm{~mm}$ shell height (Saucedo and Monteforte 1997a). Conversely, juvenile P. sterna cultivated in Bahía de los Ángeles (central Gulf of California) grew twice as rapidly (7.2 to $\left.11.3 \mathrm{~mm} \mathrm{month}{ }^{-1}\right)$ in summer and autumn and 15\% slower $\left(3.6 \mathrm{~mm} \mathrm{month}^{-1}\right)$ in winter (Bückle-Ramírez et al. 1992). Discrepancies in growth patterns are likely the result of varying environmental conditions in tropical and subtropical areas; Bahía de Acapulco experiences little seasonal variation, and in our study, water temperature and chlorophyll $a$ content varied $5^{\circ} \mathrm{C}$ and $6.6 \mu \mathrm{g} \mathrm{L}^{-1}$, respectively, between winter and summer. In contrast, Bahía de La Paz $\left(24^{\circ} 16^{\prime} \mathrm{N}, 110^{\circ} 19^{\prime} \mathrm{W}\right)$ is a transitional and relatively less productive area (Sicard et al. 2006), where mean temperature and productivity values can vary $12{ }^{\circ} \mathrm{C}$ and 5-6 $\mu \mathrm{g} \mathrm{L}^{-1}$ during normal years not influenced by ENSO events (Romo-Piñera 2010, Martínez-López et al. 2001). In Bahía de los Ángeles ( $\left.28^{\circ} 56^{\prime} \mathrm{N}, 113^{\circ} 33^{\prime} \mathrm{W}\right)$, annual temperature and chlorophyll values may vary, $\sim 14{ }^{\circ} \mathrm{C}$
Los machos fueron más numerosos que las hembras durante la mayor parte del ciclo anual, y la proporción sexual de hembra a macho fue de 0.59:1. Adicionalmente, un $6 \%$ de la población muestreada se encontró sexualmente indiferenciada y un 3\% correspondió a ostras hermafroditas.

Los cambios estacionales en el índice gonádico fueron significativos $(P<0.05)$ y consistentes con las variaciones en la talla de los ovocitos, y mantuvieron una relación inversa con la temperatura del agua (fig. 4a) y la concentración de clorofila $a$ (fig. $4 \mathrm{~b}$ ). El valor máximo del índice gonádico (37\%) se observó en marzo de $2010\left(25^{\circ} \mathrm{C} ; 2.25 \mu \mathrm{g} \mathrm{L}-1\right)$ y el mínimo $(1 \%)$ en diciembre de $2009\left(28^{\circ} \mathrm{C} ; 3.1 \mu \mathrm{g} \mathrm{L} \mathrm{L}^{-1}\right)$.

La frecuencia acumulada de tallas para machos y hembras se ajustó significativamente a un modelo logístico $(r=0.99)$. Esto reveló que los machos alcanzaron la talla de primera madurez a los $50.9 \mathrm{~mm}$ de altura de la concha y las hembras a $59.5 \mathrm{~mm}$ (fig. $5 \mathrm{a}, \mathrm{b})$.

\section{DiscUSIÓN}

A nivel mundial, la mayor industria perlera se encuentra circunscrita a las regiones tropicales de Asia y el Pacífico Sur, particularmente en el norte de Australia, China, la Polinesia Francesa, Indonesia y las Filipinas (Taylor y Strack 2008). Las especies que se utilizan para el cultivo de perlas en estos paises son del género Pinctada ( $P$. fucata, P. margaritifera, $P$. maxima); no obstante, la concha nácar Pteria penguin, de distribución tropical, ha incrementado en valor para la producción de medias perlas (mabés) de alta calidad comercial (Kishore et al. 2013). De forma similar, P. sterna puede ser cultivada con éxito en ambientes tropicales, a pesar de su preferencia por climas subtropicales y templados y, por tanto, es un candidato viable para el cultivo de perlas a lo largo de la costa este del océano Pacífico latinoamericano, incluyendo México.

La tasa de crecimiento en altura de la concha de los juveniles de P. sterna fue más rápida de julio a diciembre de 2009 $\left(5.3 \mathrm{~mm} \mathrm{mes}^{-1}\right)$ y disminuyó en un $41 \%$ de enero a abril de 2010 (3 mm mes $\left.{ }^{-1}\right)$, lo cual coincidió con el inicio de la actividad reproductiva (el índice gonádico y el diámetro de los ovocitos incrementaron). Este patrón de crecimiento mantuvo una relación inversa y negativa con la temperatura del agua, con valores máximos en primavera y mínimos en verano. La tasa promedio de crecimiento calculada para este estudio $\left(4.27 \mathrm{~mm} \mathrm{mes}^{-1}\right)$ es $\sim 20 \%$ mayor que la tasa máxima de crecimiento $\left(3.5 \mathrm{~mm} \mathrm{mes}{ }^{-1}\right)$ registrada para juveniles de $P$. sterna cultivados en bahía de La Paz (sur del golfo de California) a una talla inicial de $42.9 \mathrm{~mm}$ (Saucedo y Monteforte 1997a). Por el contrario, los juveniles de P. sterna cultivados en bahía de los Ángeles (centro del golfo de California) crecieron el doble de rápido (7.2 a $11.3 \mathrm{~mm} \mathrm{mes}^{-1}$ ) en verano y otoño, y un $15 \%$ más lento (3.6 mm mes ${ }^{-1}$ ) en invierno (Bückle-Ramírez et al. 1992). Estas diferencias son posiblemente el reflejo de variaciones en las condiciones ambientales típicas de áreas tropicales y 


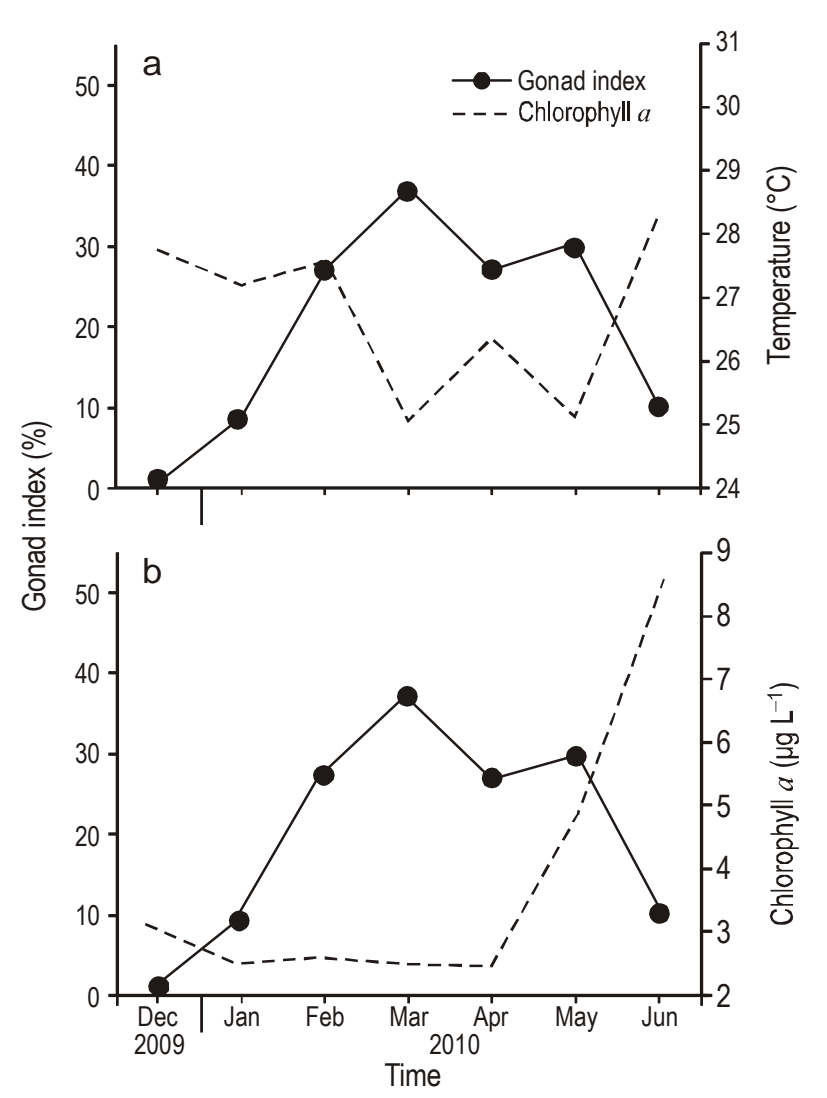

Figure 4. Seasonal changes in the gonad index of the winged pearl oyster, Pteria sterna, cultivated under suspension conditions in Bahía de Acapulco over one annual cycle, and its relation to (a) mean water temperature and (b) chlorophyll $a$ concentration.

Figura 4. Cambios estacionales en el índice gonádico de la concha nácar, Pteria sterna, mantenida bajo condiciones de cultivo en suspensión en la bahía de Acapulco durante un ciclo anual, y su relación con (a) la temperatura promedio del agua y (b) la concentración de clorofila $a$.

and $12 \mu \mathrm{g} \mathrm{L}^{-1}$, respectively (Muñoz-Barbosa et al. 1991). This site is a Biologically Active Center, with high primary productivity throughout the year and optimum conditions for filter-feeders to maintain rapid growth and reproduce continuously (Lluch-Belda 1999).

Medium-sized pearl oysters, such as $P$. sterna, grow steadily during the first year (Sims 1994). Considering that 70-80 $\mathrm{mm}$ shell height is the recommended size for grafting P. sterna at commercial pearl farms in the Gulf of California (SEMARNAT 2013; Kiefert et al. 2004; Douglas McLaurin, pers. comm.), we estimate that in Bahía de Acapulco this size is reached at an age of $15-17$ months. This timing is consistent with the age (16-18 months) when farmers graft $P$. sterna in the Gulf of California (D McLaurin, pers. comm.). Some smaller species of pearl oysters grow faster during the first 5-6 months and may reach a grafting size in 12-14 months, among them Pinctada fucata in India (Chellam 1978) and Pteria colymbus in Venezuela (Lodeiros et al.

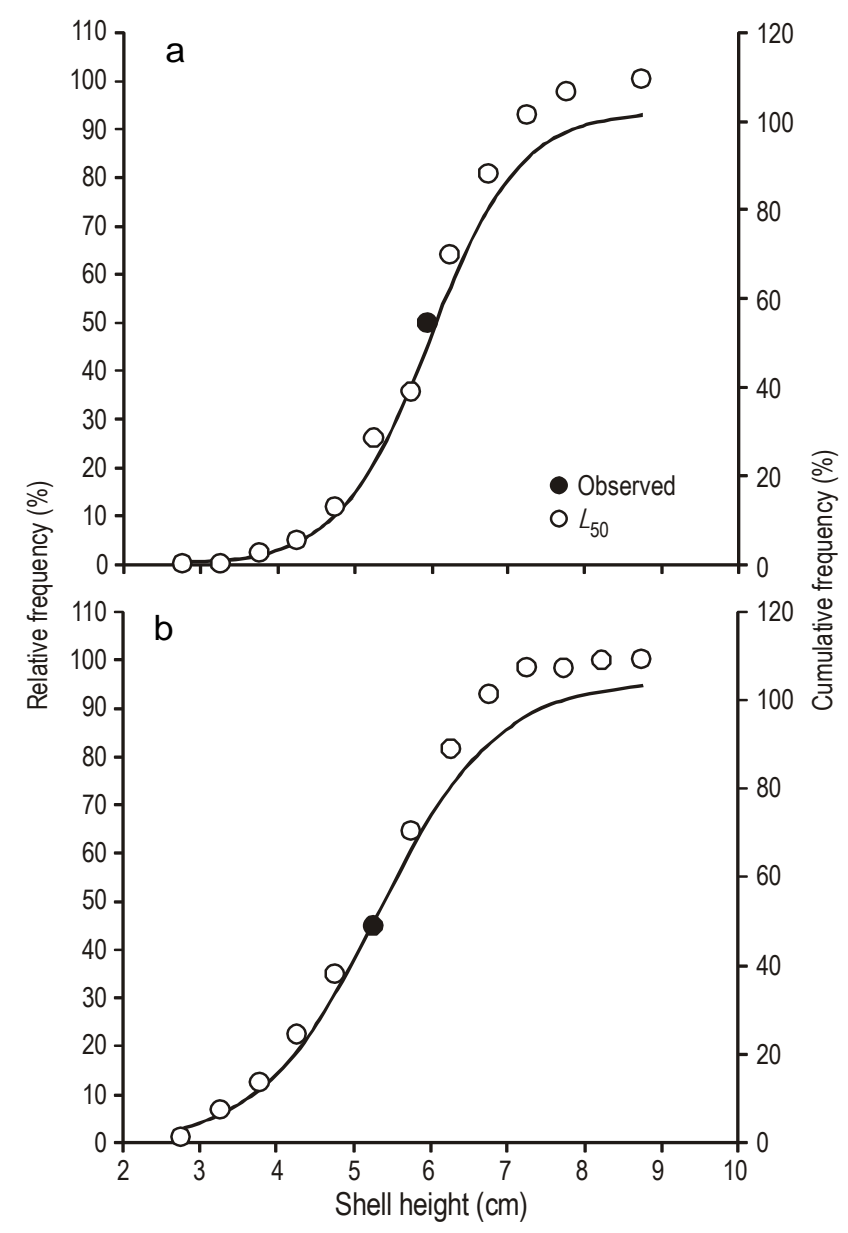

Figure 5. Relative and cumulative frequency of size data of (a) male and (b) female winged pearl oyster, Pteria sterna, cultivated under suspension conditions in Bahía de Acapulco over one annual cycle. $L_{50}$, size at first maturity.

Figura 5. Frecuencia relativa y acumulada del tamaño de (a) machos y (b) hembras de la concha nácar, Pteria sterna, mantenida bajo condiciones de cultivo en suspensión en la bahía de Acapulco durante un ciclo anual. $L_{50}$, talla de primera madurez.

subtropicales; la bahía de Acapulco presenta pocas variaciones estacionales, $\mathrm{y}$ en este estudio la temperatura del agua y la concentración de clorofila $a$ variaron $5^{\circ} \mathrm{C}$ y $6.6 \mu \mathrm{g} \mathrm{L} \mathrm{L}^{-1}$, respectivamente, entre invierno y verano. Bahía de $\mathrm{La} \mathrm{Paz}$ $\left(24^{\circ} 16^{\prime} \mathrm{N}, 110^{\circ} 19^{\prime} \mathrm{W}\right)$ es una zona transicional y relativamente poco productiva (Sicard et al. 2006), donde la temperatura del agua llega a variar en promedio $12^{\circ} \mathrm{C}$ y la productividad primaria entre 5 y $6 \mathrm{mg} \mathrm{L}^{-1}$ en años normales no influenciados por eventos ENSO (Romo-Piñera 2010, Martínez-López et al. 2001). En bahía de los Ángeles $\left(28^{\circ} 56^{\prime} \mathrm{N}, 113^{\circ} 33^{\prime} \mathrm{W}\right)$, las variaciones en la temperatura del agua y la concentración de clorofila $a$ son más marcadas y oscilan entre $\sim 14{ }^{\circ} \mathrm{C}$ y $12 \mu \mathrm{g} \mathrm{L}^{-1}$, respectivamente (MuñozBarbosa et al. 1991). Bahía de los Ángeles es un Centro de Actividad Biológica con alta productividad primaria todo el año, lo cual ofrece condiciones óptimas para el crecimiento 
1999). In contrast, $P$. penguin, a larger pearl oyster, grows up to $170-180 \mathrm{~mm}$ in shell height and requires $16-17$ months to reach a grafting size of $100 \mathrm{~mm}$ in Australia (Millione and Southgate 2012).

The von Bertalanffy growth model has been widely used in fisheries studies to compare observed and calculated data; however, it has also received criticism in regard to the accuracy of the estimated parameters. Some authors have thus proposed modifications to the equation (see Roff 1980, Ratwkosky 1986, Hernández-Llamas and Ratwkosky 2004), particularly when the age of the species is unknown or when the data do not cover a wide range of sizes to display an asymptote in the growth curve (Pouvreau and Prasil 2001). When this occurs, and the von Bertalanffy model cannot accurately determine the asymptote, the $L_{\infty}$ and $K$ parameters may be disproportionate and not comparable with values found in the literature. This may explain the highly variable growth parameters computed for juvenile $P$. margaritifera cultivated in the Cook Islands $\left(L_{\infty}=156.7\right.$ to $309.7 \mathrm{~mm}$; Sims 1994), $P$. penguin cultivated in Australia $\left(L_{\infty}=283.6\right.$ to $822.5 \mathrm{~mm}$; Millione and Southgate 2012), and P. sterna cultivated in Bahía de $\mathrm{La} \operatorname{Paz}\left(L_{\infty}=68.8 \mathrm{~mm}\right.$; Saucedo and Monteforte 1997a) and Bahía de los Ángeles $\left(L_{\infty}=146 \mathrm{~mm}\right.$; Bückle-Ramírez et al. 1992). With the proposed modification of Ratkowsky's (1986) model, it is possible to deal with the convergence of initial values and interpretation of $L_{i}$ and $L_{f}$ to describe the exponential or asymptotic growth of a species (Hernández-Llamas and Ratkowsky 2004). Compared to the von Bertalanffy model, the parameters of our model better fit the growth pattern of $P$. sterna under suspension cultivation in Bahía de Acapulco. Consistent with our findings, Lee et al. (2008) best described the growth of cultivated $P$. maxima in Indonesia with a special modification of the von Bertalanffy model (the other tested models were the Gompertz, Richards, and logistic models).

Pteria sterna started gametogenesis in December 2009 at $50.9 \mathrm{~mm}$ (males) and $59.5 \mathrm{~mm}$ (females); there was no evidence of sexual activity at smaller sizes. Comparatively, the species matures at $39 \mathrm{~mm}$ in Bahía de La Paz (Saucedo and Monteforte 1997b) and at $63 \mathrm{~mm}$ (males) and $75 \mathrm{~mm}$ (females) in Bahía de los Ángeles (Ana Karen MezaBuendía, unpublished data). In December, only $7 \%$ of the gonads were developing and $93 \%$ were spent, suggesting that gametogenesis at this point was incipient and ended with either a brief spawning event that was histologically undetectable or a rapid regression of unreleased and unfertilized gametes, as a result of weak physiological mechanisms in juveniles to sustain gametogenesis (Cáceres-Puig et al. 2009). After December, gonad development and spawning were continuous and peaked in March. This reflects the typical behavior of a tropical species (Freites et al. 2010), as well as the multi-spawning character of $P$. sterna. In the Gulf of California, the species displays peak spawning activity in December, February, and August in Bahía de los Ángeles (Hernández-Díaz and Bückle-Ramírez 1996) and from rápido y la reproducción continua de organismos filtradores (Lluch-Belda 1999).

Se ha reportado que las ostras perleras de talla media, como P. sterna, crecen de forma constante durante el primer año de vida (Sims 1994). Considerando que 70-80 mm de altura de la concha es la talla recomendada para injertar P. sterna en las granjas perleras del golfo de California (SEMARNAT 2013; Kiefert et al. 2004; Douglas McLaurin, com. pers.), se estima que en la bahía de Acapulco esta talla se alcanza entre 15 y 17 meses de edad. Este tiempo es consistente con la edad (16-18 meses) a la que se injerta P. sterna en Guaymas, Sonora (D McLaurin, com. pers.). Otras especies de ostras perleras de menor talla crecen rápidamente durante los primeros 5-6 meses y pueden alcanzar la talla de injerto en 12-14 meses, entre éstas, Pinctada fucata en la India (Chellam 1978) y Pteria colymbus en Venezuela (Lodeiros et al. 1999). Por el contrario, P. penguin es de mayor talla y alcanza hasta 170-180 mm de altura, por lo que requiere entre 16 y 17 meses para alcanzar la talla comercial de injerto de $100 \mathrm{~mm}$ en Australia (Millione y Southgate 2012).

El modelo clásico de crecimiento de von Bertalanffy ha sido ampliamente utilizado en estudios de pesquerías para comparar datos observados y calculados; sin embargo, también ha recibido críticas en lo referente a la precisión de los parámetros estimados. Por tanto, algunos autores han propuesto modificaciones a la ecuación general (ver Roff 1980, Ratwkosky 1986, Hernández-Llamas y Ratwkosky 2004), particularmente cuando la edad de la especie se desconoce o cuando los datos no cubren un intervalo amplio de tallas para mostrar una asíntota en la curva de crecimiento (Pouvreau y Prasil 2001). Cuando esto ocurre, y el modelo de von Bertalanffy no puede determinar con precisión la asíntota en la curva de crecimiento, los parámetros de $L_{\infty}$ y $K$ pueden estar desproporcionados y no ser comparables con los valores registrados en la literatura. Esto podría explicar los parámetros de crecimiento tan variables que se han registrado para juveniles cultivados de algunas especies de ostras perleras como $P$. margaritifera en las islas Cook $\left(L_{\infty}=156.7\right.$ a $309.7 \mathrm{~mm}$; Sims 1994), P. penguin en Australia $\left(L_{\infty}=283.6\right.$ a $822.5 \mathrm{~mm}$; Millione y Southgate 2012) y P. sterna en bahía de La Paz $\left(L_{\infty}=68.8 \mathrm{~mm}\right.$; Saucedo y Monteforte 1997a) y bahía de los Ángeles $\left(L_{\infty}=146 \mathrm{~mm}\right.$; Bückle-Ramírez et al. 1992). La propuesta de modificar el modelo de Ratkowsky (1986) permite lidiar con la convergencia de los valores iniciales y la interpretación de los parámetros de $L_{i}$ y $L_{f}$ para la descripción del crecimiento exponencial o asintótico de una especie (Hernández-Llamas y Ratkowsky 2004). En comparación con el modelo de von Bertalanffy, los parámetros del modelo propuesto en este estudio se ajustaron mejor al patrón de crecimiento de P. sterna cultivada en la bahía de Acapulco. Lee et al. (2008) también registraron que el crecimiento de $P$. maxima cultivada en Indonesia se describe de forma más precisa con una modificación especial del modelo de von Bertalanffy (los 
February to May in Bahía de La Paz (Saucedo and Monteforte 1997b, Vite-García and Saucedo 2008). Overall, these peaks in spawning activity correspond to decreasing water temperatures from late winter $\left(25^{\circ} \mathrm{C}\right)$ to early spring $\left(22^{\circ} \mathrm{C}\right)$. In our study, these temperatures occurred mostly in February and March and coincided with the main spawning peak, high gonad index, and larger oocytes. Based on these data, we assume that the species is energetically strong and prepared for grafting operations in winter and spring. In contrast, temperatures in summer are high and the oysters are likely exhausted and therefore not recommendable for use in pearl cultivation. In support of this assumption, GonzálezJiménez (2013) reported that the optimum scope for growth of $P$. sterna occurs at $22^{\circ} \mathrm{C}$ and the critical limit is $28^{\circ} \mathrm{C}$.

We detected an inverse relationship between gonad activity and environmental factors. Overall, the maximum gonad index and oocyte diameter coincided with low temperatures and low chlorophyll $a$ content. This scenario suggests that $P$. sterna uses a conservative strategy to regulate gametogenesis in spring in tropical environments, mainly sustained by energy reserves stored in somatic tissues. In contrast, the species relies on a combination of conservative and opportunistic strategies to support gametogenesis in subtropical areas (Bahía de La Paz), firstly using energy from food when primary productivity is high in winter, and then using energy from stored reserves in spring when productivity declines (Vite-García and Saucedo 2008, Cáceres-Puig et al. 2009).

Our results show that $P$. sterna grows quickly under the tropical conditions of Bahía de Acapulco and can reach the grafting size of $70-80 \mathrm{~mm}$ in $15-16$ months. We also noted that the species uses a different strategy for channeling available energy into growth and reproduction in Bahía de Acapulco, compared to subtropical areas. These findings not only provide a better understanding of the physiological needs of the species over a wide geographic range in Mexico, but are also relevant for the potential development of pearl farms in Bahía de Acapulco. In this area, we recommend grafting $P$. sterna in winter and spring.

\section{ACKNOWLEDGMENTS}

This project was funded by the National Council for Science and Technology (CONACYT, Mexico, grant 81249) and the CONACYT/Guerrero State Government Joint Fund (grant 2008-01). The study is part of the MSc thesis of ISG, who acknowledges receipt of a CONACYT scholarship. We are grateful to Carmen Rodríguez-Jaramillo and María Eulalia Meza-Chávez (CIBNOR) for processing histological samples and to Diego García-Paredes (UAN) for field assistance. We also thank Ira Fogel (CIBNOR) for English editing services. Douglas McLaurin, professional grafter of the company Perlas del Mar de Cortez, provided valuable unpublished data. otros modelos evaluados fueron el modelo de Gompertz, el de Richards y el logístico).

Pteria sterna inició la gametogénesis en diciembre de 2009, a una talla promedio de $50.9 \mathrm{~mm}$ (machos) y $59.5 \mathrm{~mm}$ (hembras); no hubo evidencia de actividad reproductiva a tallas menores. Se ha registrado que la especie madura a una talla de $39 \mathrm{~mm}$ en bahía de La Paz (Saucedo y Monteforte 1997b) y a $63 \mathrm{~mm}$ (machos) y $75 \mathrm{~mm}$ (hembras) en bahía de los Ángeles (Ana Karen Meza-Buendía, datos no publicados). En diciembre, la presencia de gónadas en desarrollo fue tan sólo del $7 \%$ y en estadio de postdesove del $93 \%$. Este resultado sugiere que la gametogénesis en diciembre fue incipiente y finalizó ya sea con un breve desove que no se detectó histológicamente, o con una rápida reabsorción de los gametos no liberados al medio para la fertilización, posiblemente como reflejo de un débil mecanismo de los juveniles para sustentar la gametogénesis (Cáceres-Puig et al. 2009). Después de diciembre, la gametogénesis y el desove ocurrieron de forma continua todo el año, y alcanzaron un pico máximo en marzo. Esto confirma el comportamiento típico de una especie tropical (Freites et al. 2010), así como el carácter multi-desovador de $P$. sterna. En el golfo de California, la especie presenta picos en la actividad de desove en febrero y agosto en bahía de los Ángeles (Hernández-Díaz y Bückle-Ramírez 1996) y de febrero a mayo en bahía de La Paz (Saucedo y Monteforte 1997b, Vite-García y Saucedo 2008). En general, estos picos de desove coinciden con la disminución en la temperatura del agua entre invierno $\left(25^{\circ} \mathrm{C}\right)$ y primavera $\left(22^{\circ} \mathrm{C}\right)$. En el presente estudio, estas temperaturas ocurrieron en febrero y marzo y coincidieron con el pico principal de desove y con los valores máximos del índice gonádico y del diámetro de ovocitos. Con base en estos resultados, se supuso que la especie se encontraba energéticamente más fuerte y preparada para soportar la cirugía del injerto en invierno y primavera. En contraste, las temperaturas del agua en verano son altas y las ostras están energéticamente agotadas, por lo que su uso para la perlicultura no es recomendable. En apoyo a esta sugerencia, GonzálezJiménez (2013) documentó que el marco óptimo para la actividad de $P$. sterna se alcanza a los $22^{\circ} \mathrm{C}$ y el límite crítico a $\operatorname{los} 28^{\circ} \mathrm{C}$.

La actividad reproductiva estuvo inversamente relacionada con los factores ambientales. En general, los valores máximos del índice gonádico y el diámetro de ovocitos se correspondieron con valores bajos de la temperatura del agua y de la concentración de clorofila $a$. Esto sugiere que, en ambientes tropicales, P. sterna utiliza una estrategia conservadora para regular la gametogénesis en primavera, principalmente a partir de la energía almacenada en tejidos somáticos. En cambio, la especie utiliza una combinación de estrategias, conservadora y oportunista, para sostener la gametogénesis en ambientes subtropicales (bahía de La Paz), primero a partir de la energía tomada del alimento cuando la productividad primaria es alta en invierno y luego de las reservas energéticas en primavera cuando la productividad 


\section{REFERENCES}

Bückle-Ramírez LF, Voltolina-Lobina D, Morales-Guerrero E, Valenzuela-Buriel F. 1992. Spat settlement and growth of Pteria sterna (Gould) (Mollusca, Bivalvia) in Bahía de los Ángeles, Baja California, Mexico. Trop. Ecol. 33: 137-147.

Cáceres-Puig JI, Cáceres-Martínez C, Saucedo PE. 2009. Annual reproductive effort of Pacific winged pearl oyster Pteria sterna and its relation with the timing for planning pearl seeding operations. J. Shellfish Res. 28: 471-476.

Campbell A, Ming MD. 2003. Maturity and growth of Pacific geoduck clam, Panopea abrupta, in southern British Columbia, Canada. J. Shellfish Res. 22: 85-90.

Cantú-Cantú P. 2003. Crecimiento y supervivencia en fase de preengorda de la concha nácar Pteria sterna (Gould 1851) en un sistema de cultivo de suspensión bajo diferentes densidades con semilla silvestre en la Bahía de Acapulco, Guerrero (México): julio de 2001 a enero de 2002. In: Memorias del Congreso Iberoamericano Virtual de Acuicultura (CIVA, http:// www.revistaaquatic.com/civa2003), pp. 161-176.

Cariño MM, Monteforte M. 1995. History of pearling in the Bay of La Paz, South Baja California, Mexico (1533-1914). Gems Gemol. 31: 88-108.

Chellam A. 1978. Growth of pearl oyster Pinctada fucata in the pearl culture farm at Veppalodai. Indian J. Fish. 25: 77-83.

Fong QSW. 2005. Economic feasibility of small-scale black-lipped pearl oyster (Pinctada margaretifera) pearl farming in the Central Pacific. Aquacult. Econ. Manage. 9: 347-368.

Freites L, Montero L, Arrieche D, Babarro JM, Saucedo PE, Córdova C, García N. 2010. Influence of environmental factors on the reproductive cycle of the eared ark Anadara notabilis (Röding 1798) in northeastern Venezuela. J. Shellfish Res. 29: 69-75.

González-Jiménez A. 2013. Efecto de la temperatura y concentración de alimento sobre la ecofisiología de la concha nácar Pteria sterna bajo condiciones controladas de laboratorio. MSc thesis, Universidad del Mar, Puerto Ángel, Oaxaca, Mexico, $98 \mathrm{pp}$.

Grant A, Tyler PA. 1983. The analysis of data in studies of invertebrate reproduction. II. The analysis of oocyte size/ frequency data, and comparison of different types of data. Int. J. Invert. Reprod. 6: 271-283.

Hadj-Taieb A, Ghorbel M, Hadj-Hamida NB, Jarboui O. 2013. Sex ratio, reproduction, and growth of the gilthead sea bream, Sparus aurata (Pisces: Sparidae), in the Gulf of Gabes, Tunisia. Cienc. Mar. 39: 101-112.

Heffernan P, Walker L, Carr J. 1989. Gametogenic cycles of three bivalves in Wassaw Sound, Georgia. I. Mercenaria mercenaria (Linnaeus 1758). J. Shellfish Res. 8: 51-60.

Hernández-Díaz A, Bückle-Ramírez LF. 1996. Gonadal cycle of Pteria sterna (Gould 1851) (Mollusca, Bivalvia) in Baja California, Mexico. Cienc. Mar. 22: 495-509.

Hernández-Llamas A, Ratkowsky DA. 2004. Growth of fishes, crustaceans and molluscs: estimation of the von Bertalanffy, Logistic, Gompertz and Richards curves and a new growth model. Mar. Ecol. Prog. Ser. 282: 237-244.

Keen M. 1971. Sea Shells of Tropical West America. Marine Mollusks from Baja California to Peru. 2nd ed. Stanford University Press, Stanford, California, 1064 pp.

Kiefert L, McLaurin D, Arizmendi E, Hänni HA, Elen S. 2004. Cultured pearls from the Gulf of California, Mexico. Gems Gemol. 40: 26-38.

Kim Y, Ashton-Alcox KA, Powell EN. 2006. Histological Techniques for Marine Bivalve Molluscs: Update. NOAA declina (Vite-García y Saucedo 2008, Cáceres-Puig et al. 2009).

Los resultados de este estudio muestran que P. sterna crece rápidamente en las condiciones tropicales de la bahía de Acapulco y puede alcanzar la talla sugerida de injerto de 70-80 $\mathrm{mm}$ en $15-16$ meses. La especie utiliza estrategias diferentes para canalizar la energía disponible del medio para actividades de crecimiento y reproducción en la bahía de Acapulco, en comparación con otras áreas subtropicales o templadas. Estos hallazgos no sólo proveen un mejor entendimiento de los requerimientos físiológicos de la especie a lo largo de un gradiente de distribución geográfica más amplio en México, sino que son relevantes para el establecimiento potencial de granjas perleras en la bahía de Acapulco. En esta área, se recomienda injertar $P$. sterna en invierno y primavera.

\section{Agradecimientos}

El presente estudio fue financiado por el Consejo Nacional de Ciencia y Tecnología (CONACYT, México, proyecto No. 81249) y el Fondo Mixto CONACYT-Gobierno del Estado de Guerrero (proyecto no. 2008-01). El estudio fue parte de una tesis de maestría de ISG, quien fue recipiente de una beca de CONACYT. Los autores agradecen a Carmen Rodríguez-Jaramillo y María Eulalia Meza-Chávez (CIBNOR) su ayuda en el procesamiento histológico de muestras y a Diego García-Paredes (UAN) el apoyo durante las salidas de campo. Se agradece también a Ira Fogel (CIBNOR) la edición del texto en inglés. Douglas McLaurin, injertador profesional de la compañia Perlas del Mar de Cortez proporcionó información valiosa no publicada.

Technical Memorandum NOS NCCOS 27, Silver Spring, Maryland, $64 \mathrm{pp}$.

Kishore P, Southgate PC, Seeto J, Hunter J. 2013. Factors influencing the quality of half-pearls (mabé) produced by the winged pearl oyster, Pteria penguin (Röding 1758). Aquacult. Res.: $1-8$ http://dx.doi.org/10.1111/are.12228

Lee AM, Williams A, Southgate PC. 2008. Modelling and comparison of growth of the silverlip pearl oyster Pinctada maxima (Jameson Mollusca: Pteriidae) cultured in west Papua, Indonesia. Mar. Freshwat. Res. 59: 22-31.

Lodeiros CJ, Rengel JJ, Himmelman JH. 1999. Growth of Pteria colymbus (Roding 1798) in suspended culture in Golfo de Cariaco, Venezuela. J. Shellfish Res. 18: 155-158.

Lluch-Belda D. 1999. Centros de Actividad Biológica en la costa de Baja California. In: Lluch-Belda D, Elorduy-Garay J, LluchCota SE, Ponce-Díaz G (eds) BAC's: Centros de Actividad Biológica del Pacífico Mexicano. Centro de Investigaciones Biológicas del Noroeste. La Paz, Mexico, pp. 49-64.

Martínez-Fernández E, Acosta-Salmón H, Rangel-Dávalos C. 2004. Ingestion and digestion of ten species of microalgae by winged pearl oyster Pteria sterna (Gould 1851) larvae. Aquaculture 230: 419-425. 
Martínez-López A, Cervantes-Duarte R, Reyes-Salinas A, ValdezHolguín JE. 2001. Cambio estacional de clorofila $a$ en la Bahía de La Paz, BCS, México. Hidrobiologica 11: 45-52.

McLaurin-Moreno D, Arizmendi-Castillo E. 2002. Five centuries of Mexican pearls. Australian Gemmologist. 21: 190-201.

McLaurin-Moreno D, Arizmendi-Castillo E, Farell S, Nava M. 1997. Pearls and pearl oysters from the Gulf of California, Mexico: An update. Australian Gemmologist. 19: 497-502.

Millione M, Southgate PC. 2012. Growth of the winged pearl oyster, Pteria penguin, at dissimilar sites in northeastern Australia. J. Shellfish Res. 31: 13-20.

Monteforte M. 2013. Instalación y operación de granjas perleras: Un manual para Pinctada mazatlanica y Pteria sterna. Editorial Academica Española, Barcelona, España, 184 pp.

Monteforte M, Bervera H, Ramírez JJ, Saucedo PE, López C. 2005. Effect of stocking density on growth and survival of the rainbow pearl oyster Pteria sterna (Gould 1852) during nursery and late culture in Bahía de La Paz, BCS, Mexico. Aquacult. Int. 13: 391-407.

Muñoz-Barbosa A, Gaxiola-Castro G, Segovia-Zavala JA. 1991. Temporal variability of primary productivity, chlorophyll and seston in Bahía de los Ángeles, Gulf of California. Cienc. Mar. 17: 47-68.

Pouvreau S, Prasil V. 2001. Growth of the blacklip pearl oyster, Pinctada margaritifera, at nine culture sites in French Polynesia: Synthesis of several sampling designs conducted between 1994 and 1999. Aquat. Living Resour. 145: 155-163.

Ratkowsky DA. 1986. Statistical properties of alternative parameterizations of the von Bertalanffy growth curve. Can. J. Fish. Aquat. Sci. 43: 742-747.

Roff DA. 1980. A motion for the retirement of the von Bertalanffy function. Can. J. Fish. Aquat. Sci. 37: 127-129.

Romo-Piñera AK. 2010. Estrategia reproductiva de Megapitaria squalida (Sowerby 1835) en dos zonas de Baja California Sur, Mexico. PhD thesis, Centro Interdisciplinario de Ciencias Marinas del IPN, La Paz, BCS, Mexico, 107 pp.

Ruíz-Rubio H, Acosta-Salmón H, Olivera A, Southgate PC, RangelDávalos C. 2006. The influence of culture method and culture period on quality of half-pearls ('mabe') from the winged pearl oyster Pteria sterna, Gould 1851. Aquaculture 254: 269-274.

Ruíz-Velazco JMJ, Hernández-Llamas A, Gómez-Muñoz VM, Magallón FJ. 2010. Dynamics of intensive production of shrimp Litopenaeus vannamei affected by white spot disease. Aquaculture 300: 113-119.
Saucedo PE, Monteforte M. 1997a. In situ growth of pearl oyster Pinctada mazatlanica (Hanley 1856) and Pteria sterna (Gould 1851) under repopulation conditions at Bahía de La Paz, Baja California Sur, Mexico. Aquac. Res. 28: 367-368.

Saucedo PE, Monteforte M. 1997b. Breeding cycle of pearl oysters Pinctada mazatlanica and Pteria sterna (Bivalvia: Pteriidae) at Bahia de La Paz, Baja California Sur, Mexico. J. Shellfish Res. 16: 103-110.

Saucedo PE, Monteforte M, Blanc F. 1998. Changes in shell dimensions of pearl oysters Pinctada mazatlanica (Hanley 1856) and Pteria sterna (Gould 1851) during growth as criteria for Mabé pearl implants. Aquacult. Res. 29: 801-814.

SEMARNAT. 2013. Norma Oficial Mexicana NOM-058-PESC/ SEMARNAT-2010. Regulación del cultivo de las ostras perleras: madreperla (Pinctada mazatlanica), concha nácar (Pteria sterna), madreperla del Atlántico (Pinctada imbricata) y la ostra perlera alada del Atlántico (Pteria colymbus) en aguas marinas de jurisdicción federal de los Estados Unidos Mexicanos. Diario Oficial de la Federación. Mexico City.

Sicard MT, Maeda-Martínez AN, Lluch-Cota SE, Lodeiros CJ, Roldán-Carrillo L, Mendoza-Alfaro R. 2006. Frequent monitoring of temperature: An essential requirement for site selection in bivalve aquaculture in tropical-temperate transition zones. Aquacult. Res. 37: 1040-1049.

Sims NA. 1994. Growth of wild and cultured black-lip pearl oysters Pinctada margaritifera (L.) (Pteriidae; Bivalvia) in the Cook Islands. Aquaculture 122: 181-191.

Sokal RR, Rohlf FJ. 1981. Biometry. 2nd ed. WH Freeman, San Francisco, California, $891 \mathrm{pp}$.

Taylor J, Strack E. 2008. Pearl production. In: Southgate PC, Lucas JS (eds.), The Pearl Oyster: Biology and Culture. Elsevier Science Publishers, Amsterdam, pp. 273-302.

Torres-Zepeda MG, Morales-Salvador J, Peralta-Montes L. 2002. Evaluación de la captación estacional y batimétrica de semilla de la madreperla Pinctada mazatlanica (Hanley 1856) y la concha nácar Pteria sterna (Gould 1851) en colectores artificiales en la Bahía de Acapulco (Guerrero, México). In: Memorias del Congreso Iberoamericano Virtual de Acuicultura (CIVA, http:// www.revistaaquatic.com/civa2002), pp. 388-408.

Vite-García MN, Saucedo PE. 2008. Energy storage and allocation during reproduction of pearl oyster Pteria sterna (Gould 1851) at Bahía de La Paz, Baja California Sur, México. J. Shellfish Res. 27: 375-383.

Received January 2014, accepted April 2014. 